\title{
The Role of Human Resource Management in Developing the Human Capital for Global Excellence-An Empirical Study
}

\author{
Dr. Kapil Bansal ${ }^{1}$ \\ ${ }^{1}$ Assistant Professor, Institute of Business Management, GLA University, Mathura, India. \\ E-mail: kapil.bansal@gla.ac.in
}

Article History: Received: 11 January 2021; Accepted: 27 February 2021; Published online: 5 April 2021

\begin{abstract}
Companies currently are facing various crucial business challenges; Intellectual capital, Technology, Globalization, Profitability through growth, and Change. These challenges require organizations to build new capabilities in a collaborative manner, and it is human resource management developing these capabilities. It enables the organizations by playing the leadership role in meeting competitive challenges. HR professionals have shed their traditional image of policing rule making policy. Today HR professionals are held responsible for the employee's engagement and commitment towards the organization and making them contribute and stepping into the shoes of ownership. It is no longer administrative dinosaur. It has changed from a narrow picture, reactive role to a much wider canvas. By bringing the management of the organization together with the employees, a new management of human resources triggers, a merging of the reservoir of knowledge of the person and the organization, culminating in the combined triumph of both. Competitiveness at the global level can be achieved not by only using the upgraded technologies and facilities, but by motivating employees efficiently and effectively, to comply with universal standards. Every company on the world stage, human resources professionals have the mission to affect the business world; HR is now on a paradigm shift and as a support function, withered on the board, called on to help others and to hire and fire from the companies are rapidly eroding. Human resources playing a very proactive role in managing the problems of globalization. It brings change and improves the individuals' ability to learn and collaborate, manage diversity, ambiguity and complexity. The research is an attempt to understand the role of HRM in building national talent for global achievement and to study and compare the perception of corporate employees, management faculties \& management students.
\end{abstract}

Keywords: Human Resource, Challenges, Leadership Role.

\section{Introduction}

The early days of human resources out performed employee training programs. Although traditional activities are still important, HR muscle is provided by modern hr professionals. On the day, you made this strategy of 'companies' through the broad range of 'business skills' knowledge and experience. More important, the impact of human resource contributions from productivity is the determining factor. Human Resource should be deeply anchored and aligned to the business environment in today's global economy, and HR function should play an instrumental role in anticipating change and implementing change for the active mobility of people worldwide. Continuous skill development is the most important engine for business success in the rapidly changing global economy. The only way to preserve the sustainability of productivity and profitability of all the company's stakeholders, from senior management to the youngest operator. Filling this skill gap will ensure the companies to reach that position which will be helpful for now and near future. The Human Resources deals directly and indirectly with all those intangibles, which is very important in today's era of globalization.

HR professionals have shelved their traditional image of polishing rule making policy. Today HR professionals are held responsible for engagement, commitment and contribution. It is no longer administrative dinosaur.

It has grown from a close interview, reactive role to a much big big canvas. Uniting the leadership a new management of human resources begins to merge the reservoir of knowledge of the individual and the organization, resulting in the combined victory of the two.

HR should focus on creating challenged, empowered; excited rewarded teams of people, and it should be the outspoken advocate of employee interests for global excellence. HR professionals must accept that continuous learning is an integral part of the modern workplace especially global HR professionals.

"HR objectives are also evolving," says Brewster. "New demands are placed on HR staff to develop leaders, maintain quality manpower and increase productivity in the face of increased global competition." As a result, these companies are trying to put in place a comprehensive human resources policy with a minimum of countryspecific adaptations.

As Vladimir Pucik wrote in "Globalization and Human Resource Management", "Core competencies invisible assets, and organizational capabilities are key factors influencing long term success in global markets. Thus, we are witnessing a renewed interest in human resource management as a major strategic tool that can uphold the competitive position of a global firm." "Good HR management in a global context comes down to 
getting the right people in the right places at the right times and at the right costs. These international managers must then be meshed into a cohesive network in which they quickly identify and leverage good ideas worldwide."

Human Resources professionals in multinational companies perform the following activities:

John Quelch

- Equip new skills, the most experienced people, regardless of their origin, and retain talent worldwide.

- Train leaders who can think, inspire and act on the world stage.

- Increase the role of human resources as a strategic business partner.

Internationally, traditional activities are becoming more complex. HR professionals in national enterprises are subject to the social security standards, labor legislation and tax requirements of a single national government. HR professionals have to design and manage tailored programs for employees who are travelling from different countries with different environment and legal requirements. They must not only fight against legal differences, but also against cultural differences.

\section{Review of Literature}

Ulrich (1999) has defined four roles for HR professionals in this new compact HR environment: Providing feedback on performance, executive coaches, organizational architects, action plan development, builders who apply human resources management best practices for the implementation of the strategy and team leaders, manage change and model the set of values that enables the business to succeed.

"Strategic contribution turns out to be the most important of the five competencies for HR professionals to have" Wilhelm (2001) president of Global Consulting Alliance (left) and a co-author of the HR survey.

"HR goals are also changing," Brewster (1995) "New demands are being placed on HR staff to develop leaders, retain quality workforces, and increase productivity in the face of heightened global competition."

The search for high and medium-level skills and competencies is now an international issue. This has started the active mobility of people around the world. As a result, the profile of the company's employees has become increasingly international and spread across many countries. This has resulted in a greater diversity of human resources being used at various workplaces both within and within the country. It is therefore necessary to overcome these cultural differences between the countries in which the company has developed, in order to keep productivity and profitability at the level of global competitors. MURTY (2005).

As with the changing pace of time, the workforce is more knowledgeable and more technologically upgraded, hence one may be tempted to think the opposite, i.e., the worker management would require less HR experience.

\section{Objectives of the Study}

The study was undertaken with the following objectives:

- To assess the role of HR in developing the human capital for global excellence.

- To find the various factors of HRM for developing national talent for global achievement.

- To study the perception of corporate employees to assess the role of HRM in building national talent for global achievement.

- To study the perception of Management faculties to assess the role of HRM in building national talent for global achievement.

- To study the perception of Management students to assess the role of HRM in building national talent for global achievement.

- To compare the perception of corporate employees, management faculties and management students on the role of HRM in building national talent for global achievement.

\section{Hypothesis}

The study was carried out by formulating following hypotheses:

1. There is no significant difference between the perception of corporate employees \& management faculties on the role of HRM in global arena.

2. There is no significant difference between the perception of management faculties and management students on the role of HRM in global arena.

3. There is no significant difference between the perception of corporate employees and management students on the role of HRM in global arena. 


\section{Methodology}

The study was exploratory in nature and aimed to find the various factors of HRM that contributes in developing talent for global excellence and to study the perception of corporate employees, management faculties \& management students on the role of HRM in global arena.

\section{(A) The Sample}

The respondents were selected through stratified random sampling. The size of sample was limited to 120.The target group of respondents were corporate employees, management faculties \& management students.

\section{(B) The Tools}

a) For Data Collection

Data was collected by using the questionnaire method. The questionnaire consisted of 36 statements. The questions were direct and indirect. The questionnaires were administered personally to the respondents.

b) For Data Analysis

The raw data was tabulated taking in to account three categories of respondents. After, all the responses were compiled, item to total correlation and factor analysis was applied to find out the various factors which contribute more. Mean \& SD was applied to compare the perception of three categories of respondents' i.e. corporate employees, Management faculties and Management students and Z -test was also applied to test the significance of difference between corporate employees \& Management faculties, Management faculties and Management students, corporate employees\& Management students.

\section{Results}

The results obtained through research are as follows:

(1) The mean value of all the respondents is 134.06 and SD is 16.42.

(2) The eleven factors identified are:

- HR for growth and innovation

- HR for discovering potential

- HR for self-development

- HR for unity in diversity

- HR for sustained development

- HR for honing future capabilities

- HR for Change management

- HR for business excellence

- HR for global excellence

- Changing perspectives of HR

- HR for global career planning

(3) Mean, SD and Z-value comparison of respondents on role of HRM in building national talent for global achievement.

\begin{tabular}{lccl}
\hline \multicolumn{1}{c}{ Respondents } & Mean & SD & Z-value \\
\hline Corporate employees & 142.67 & 13.21 & 39.98 \\
Management faculties & 129.02 & 17.03 & 4.056 \\
Management students & 130.51 & 15.60 & 6.999 \\
\hline
\end{tabular}

\begin{tabular}{lll}
\hline Number & Hypothesis & Results \\
\hline H01 & $\begin{array}{l}\text { There is no significant difference between the perception of corporate employees \& } \\
\text { management faculties on the role of HRM in global arena. }\end{array}$ & Accepted \\
H02 & $\begin{array}{l}\text { There is no significant difference between the perception of management faculties and } \\
\text { management students on the role of HRM in global arena. } \\
\text { There is no significant difference between the perception of corporate employees and } \\
\text { management students on the role of HRM in global arena. }\end{array}$ & Accepted \\
H03 & Accepted \\
\hline
\end{tabular}

\section{Discussion}

The present study was an attempt to understand the role of HRM in building national talent for global achievement and to study and compare the perception of corporate employees, management faculties and management students on the same.

a) The results obtained indicate that the human resource management plays an important role in building national talent for global achievement and various identified factors constituted of: 
Factor 1- HR for growth and innovation, is constituted of items: (8) HRM is intrinsically linked to the success of business venture in global arena. (9) The human resource development gives an understanding to the employees of their role and importance to business performance. (13)HR leader develops a spirit of freedom and liberty that motivates people to use their imagination, express their individuality and exercise leadership. (14) HR maximizes individual growth and autonomy with increased responsibility.(17) HR play an important role in convincing people to take overseas assignments.(29) HR increases individual's ability to manage diversity \& cross cultural differences, with a total factor load of 9.10378 and constitutes $26 \%$ variance.

Factor 2-HR for discovering potential is constituted of items: (6) HR professionals are in the business of affecting the business. (10)HR activities help individuals in discovering and exploiting their own potential for their own and organization. (11)HR Professionals encourages an atmosphere where everyone learns constantly. (12) Proactivity and experimentation is being promoted by human resource development, with a total factor load of 2.24513 and constitutes $6.4 \%$ variance.

Factor 3-HR for self-development is constituted of items: (21) HR professionals are using multiple approaches to enhance global leaders. (22)The employee development programmes encompass: Self-directed leadership, with a total factor load of 1.92259 and constitutes $5.5 \%$ variance.

Factor 4-HR for unity in diversity is constituted of items:(20) The training include such programmes which can develop employees who can produce at the level of world competitive levels.(25) HR function such as manpower compensation has been tuned to address the need of global leaders.(26) HR professionals are coaches for global leaders, providing performance feedback. (27) HR professionals develop the people to take key positions throughout the world.(28)HR increases individual's ability to learn and collaborate in uncertain environment.(29) HR increases individual's ability to manage diversity \& cross cultural differences, with a total factor load of 1.77272 and constitutes $5.1 \%$ variance.

Factor 5-HR for sustained development is constituted of items: (16) HR vision is the driving force which provides a long- term direction towards building the competencies of the employees and motivating them. (31)HR professionals train employees to manage different geographies, cultures, laws \& business practices. (32) HR trains employees for uncertainty avoidance, with a total factor load of 1.72227 and constitutes $4.9 \%$ variance.

Factor 6-HR for honing future capabilities is constituted of items:(3) People's skills are an essential part of the repertoire of today's HR manager. (7)HR enables the people of organization to be customer focused, cost conscious \& quality driven. (15)HR builds future capabilities of individuals, with a total factor load of 1.45405 and constitutes $4.2 \%$ variance.

Factor 7-HR for Change management is constituted of items: (1) HRM is no more a support function. (18)HRD help employees in a planned and continuous way to acquire and sharpen capabilities required to perform various functions associated with their domestic and global assignments.(23) The employee development programmes encompass: Self-generated creativity. (24) HR function such as manpower development has been tuned to address the need of global leaders. (33) HR shapes individuals for less emotional resistance to change, with a total factor load of 1.30414 and constitutes $3.7 \%$ variance.

Factor 8-HR for business excellence is constituted of items: (4) HRM's key role is to focus on organizational performance.(5)HRM deals with threats and opportunities of business, with a total factor load of 1.20954 and constitutes $3.5 \%$ variance.

Factor 9-HR for global excellence is constituted of items: (34) HR professionals manage well dual career groups.(35) Good HR practices are a guiding light for employees to be global achievers, with a total factor load of 1.19315 and constitutes $3.4 \%$ variance.

Factor 10-Changing perspectives of $\mathbf{H R}$ is constituted of items: (2) the face and the impact of HR have changed, with a total factor load of 1.10642 and constitutes $3.2 \%$ variance.

Factor 11-HR for global career planning is constituted of items: (19) The HRD activities are designed keeping the interests of employees for global achievement, with a total factor load of 1.01340 and constitutes 2.9 $\%$ variance. 


\begin{tabular}{llc}
\hline b) & Respondents & Mean \\
\hline & Corporate employees & 142.67 \\
& Management faculties & 129.02 \\
& Management students & 130.51 \\
\hline
\end{tabular}

The above table reveals:

- The mean value i.e.142.67 of corporate employees shows that they strongly agree that human resource management plays a significant role in building national talent for global achievement

- The mean value i.e.129.02 of management faculties shows that they perceive human resource management plays a significant role in building national talent for global achievement but not as strongly as corporate employees.

- The mean value i.e.130.51 of management students shows that they do agree human resource management is a significant contributor in building national talent for global achievement but less as compared to corporate employees, but at the same time more than management faculties.

\begin{tabular}{lll}
\hline c) & Respondents & SD \\
\hline & Corporate employees & 13.21 \\
& Management faculties & 17.03 \\
& Management students & 15.60 \\
\hline
\end{tabular}

The above table reveals:

The SD value i.e.13.21 of corporate employees also shows that they strongly agree that human resource management is a significant contributor in building national talent for global achievement as compared to management faculties having SD value 17.03.

The SD value i.e.15.60 of management students also shows that they strongly agree that human resource management is a significant contributor in building national talent for global achievement as compared to management faculties having SD value 17.03 but less as compared to corporate employees having SD value as 13.21 .

\section{Recent Trends and Future Directions}

- HR should be deeply anchored and aligned to the business environment in today's global economy.

- HR function should play an instrumental role in anticipating change and implementing change to set in motion active mobility of people across the globe.

- HR should focus on creating challenged, empowered, excited rewarded teams of people.

- HR should be the outspoken advocate of employee interests for global excellence.

- HR professionals must accept that continuous learning is an integral part of the modern workplace especially global HR professionals.

- They should possess the ability and attitude to constantly enhance the skills of the employees and their own.

- They should take the worker as knowledge worker and pool of talent.

- They should develop leaders who are capable of thinking, inspiring, and acting in the global arena.

- Competency mapping of key skills must be done in an objective and scientific way.

- Training programmes need to be developed to meet long-term needs for global excellence.

- Target orienteer's intervention must address the specific learning needs and problems of a target group like soft and behavioral skills, culture hurdles, language problems, religious problems, etc.

- HR professionals should manage extremely well international relocation for expatriates and their families.

- HRM process should make a deep insight in to how employees can be motivated and how an organization can tap the vast potential of human assets.

\section{Conclusion}

The research was exploratory in nature and attempted to understand the role of HRM in building national talent for global achievement and to study and compare the perception of corporate employees, management faculties $\&$ management students on the same. Also to find the various factors which contribute more. It was found that the human resource management does play a significant role but when it was compared among the three categories i.e. Corporate employees, Management faculties \& management students, corporate employees were found strongly agreeing to it as compared to management faculties and management students. And Management students were found strongly agreeing as compared to management faculties. The eleven factors identified 
were HR for growth and innovation, HR for discovering potential, HR for self-development, HR for unity in diversity, HR for sustained development, HR for honing future capabilities, HR for Change management, HR for business excellence, HR for global excellence, Changing perspectives of HR,HR for global career planning. High and medium-level skills and competencies is now an international issue. Companies currently are facing various crucial business challenges; Intellectual capital, Technology, Globalization, Profitability through growth, and Change. These challenges require organizations to build new capabilities in a collaborative manner, and it is human resource management developing these capabilities. It enables the organizations by playing the leadership role in meeting competitive challenges. This has started the active mobility of people around the world. As a result, the profile of the company's employees has become increasingly international and spreading worldwide. Huge diversity of human resources being used at various workplaces both within and within the country. It is therefore necessary to overcome these cultural differences between the countries in which the company has developed, in order to keep productivity and profitability at various levels.

\section{Limitations}

1. The sample size was small and research findings cannot be generalized.

2. The study could be done on corporate employees of service industry as well.

3. Time constraint was such that it restricted the sample to Pithampur and Indore only.

\section{References}

8. Deeprose, D. (2002). Global HR. Capstone Publishing, UK.

9. Murty, G.R.K. (2005). The Landscape of IHRM. HRM Review, 5(1).

10. Joynt \& Morton (2005). The Global HR Manager. Jaico Publishing, New Delhi.

11. Rao, Verma \& Khandelwal (2002). Alternative approaches and strategies of HRD. Rawat publications, Jaipur \& New Delhi.

12. Casccio, F.W. (1992). Managing Human Resources, Productivity QWL, Profits, Mc-Graw-Hill, USA.

13. Irancevich, M.J. (1995). Human Resource Management. IRWIN, USA.

14. Rugman \& Hodgetts. (2004). International Business. Pearson Education, Delhi.

15. Bhalla \& Ramu. (2004). International Business Environment \& Management. Anmol Publication, New Delhi.

16. Ashwathappa. (2004). International Business. Tata McGraw - Hill, New Delhi.

17. Gooderham \& Nordhaug. (2003). International Management Cross Boundary Challenges. Blackwell publishing, USA.

18. Reed, A. (2004). Innovation in Human Resource Management. Tooling of for the talent wars Jaico Publishing, Mumbai.

19. Rao, T.V. (2003). Future of HRD Mac Millan India Ltd. Delhi.

20. Kumar, H. (2003). HRM in the $21^{s t}$ century. Anmol Publication, New Delhi.

21. Sadri \& Jayshree, Ajgaonkar. (2002). Geomeatry of HR. Himalaya Publishing, Mumbai.

22. Berger \& Berger. (2004). Talent Management. Tata McGraw-Hill, Publishing, New Delhi. 